\title{
Investigation of the Attitudes of Japanese Physical Educational University Students toward Doping in Sports
}

Masato Takahashi ${ }^{1 *}$, Yukitoshi Tatsugi ${ }^{1}$ and Tosihiko Kohno ${ }^{2}$

${ }^{1}$ Faculty of Physical Education, International Budo Univ, Japan

${ }^{2}$ Faculty of Nursing, Kameda College of Health Science, Japan

\begin{abstract}
Background: Drug abuse, most notably Anabolic-Androgenic Steroid (AAS) use, in athletes is thought to be widespread. A few drug abusers and persons who express acceptance of drug abuse in sports are known to be present in Japan as well. We investigated the state of drug abuse and attitudes toward drug abuse in sports in a Japanese physical education university from the viewpoint of anti-doping.
\end{abstract}

Methods: The study sample was comprised of students attending a physical educational university in Japan. An anonymous self-completed questionnaire was given out in two classes at the beginning of the semester from 2008 until 2012, inclusive. Results for the year 2011 are given here. The questionnaire had 5 sections covering responder's drug use, attitudes toward doping, a hypothetical situation on an athlete's drug use, dietary supplements, and what the responder eats or drinks before playing a game.

Results: The response rate for the 2011 questionnaire was $100 \%$. There were 2 admitted drug abusers $(0.4 \%)$ and $774(99.6 \%)$ non-abusers. The use of diuretics was admitted. In Section II, which included a question on what the responder thought of doping, 144 (19.3\%) selected "good" and 592 (79.1\%) selected "bad". Section III presented a hypothetical situation whereby the respondent would use a drug undetectable by doping control, win a gold medal and have a lifespan of only 5 years thereafter. In answer to the question of whether the respondent would use the drug under those conditions, 85 (11.4\%) answered "yes" and 655 (87.5\%) answered "no".

Conclusions: $20 \%$ of the students approved of drug use in sports. Furthermore, based on the response to a question in Section III, it can be speculated that $10 \%$ of the students might have used drugs in sports.

Keywords: Drug abuse; Doping; Questionnaire; Survey; Stimulant; Anabolic steroid; Dietary supplement

\section{Introduction}

A famous track sprinter was ruled out of the 1988 Seoul Korea Olympics for using Anabolic-Androgenic Steroids (AAS), a case that was very shocking. Many athletes were judged positive by doping control measures for using performance enhancing drugs in the 2004 Athens Olympics, too. Drug abuse, most notably AAS use, in athletes is thought to be widespread. Therefore, various surveys on drug abuse among youth have been made in developed countries since that time. Reports of such surveys have been published from Japan also. Takahashi et al. reported on counseling of drug abusers from the viewpoint of anti-doping in Japan [1-2]. Furthermore they surveyed the state of drug abuse through a blog accessed by drug abusers [3]. The drug abusers used the Internet to gain knowledge of information on drug abuse, side effects and the role of the Internet in drug abuse. Furthermore, it was clear that drug abusers exchanged information on doping with each other by blogs.

Meilman et al. performed a cohort study of AAS abusers and nonusers by self-reported data in USA among USA college students in 1990 and 1991 [4]. An official questionnaire survey in Japanese of the state of doping and attitudes toward it was distributed at a National Athletic Meet in Japan. A few drug abusers and persons who accepted the use of such drugs were known to be present. No surveys were performed thereafter in Japan.

We have attempted to investigate the state of drug abuse and attitudes toward drug abuse in sports in a Japanese physical education university. Because physical education university students could easily become connected with drug abuse in sports, we thought that they were an appropriate sample. In addition, it is important to know the state of drug abuse in sports as well as the physical educational college students' attitude toward doping from the viewpoint of anti-doping. From results of this survey, we could clarify the circumstances surrounding permitting drug abuse in Japan and the attitude toward drug abuse in sports.

\section{Materials and Methods}

The sample studied was comprised of some of the students who attended a physical educational university, which is located in a rural area. Judo, kendo, naginata, and other Budo event teams from this university are strong in college sports. Field and track events, baseball, volleyball, lifesaving competitions, and power lifting teams are also strong. Some of the participants are candidates for Olympic events.

Participants belonged to one of two "Sports Medicine" classes or a "Health Care Studies" class. An anonymous self-completed questionnaire was given out in each class at the beginning of each semester. Such a questionnaire has been distributed every year since 2006, with the format being changed in 2008 to the one described herein In this report, we showed the results of the questionnaire distributed in 2011. Almost all of the students who completed the questionnaire were second-year students; however, a few were third- and fourth-year students. In this university, each grade consists of about 500 persons, with $16.7 \%$ being female (female's 338/total 2027). In the three classes surveyed, $15.3 \%$ were females (female's 131 /total 856 ). To protect the

${ }^{*}$ Corresponding author: Dr. Masato Takahashi, Faculty of Phys. Educ, International Budo Univ, Japan, E-mail: t-masato@budo-u.ac.jp

Received May 09, 2013; Accepted May 30, 2013; Published June 01, 2013

Citation: Takahashi M, Tatsugi Y, Kohno T (2013) Investigation of the Attitudes of Japanese Physical Educational University Students toward Doping in Sports. J Sports Med Doping Stud 3: 122. doi:10.4172/2161-0673.1000122

Copyright: (c) 2013 Takahashi M, et al. This is an open-access article distributed under the terms of the Creative Commons Attribution License, which permits unrestricted use, distribution, and reproduction in any medium, provided the original author and source are credited. 
student's anonymity, this questionnaire did not have a question on grade and gender.

We declared that results of this questionnaire would not be given to the university managers, even if someone admitted to using an illegal drug. All of the students answered the questions regarding illegal drug use.

The questionnaire consisted of 5 sections (Table 1). Section I had questions on drug abuse. The first question asked whether or not responders were using a drug and, if so, the second question asked which of the following drugs were used: stimulant, anabolic agent (AAS, $\beta_{2}$ stimulant, and growth hormone), erythropoietin, diuretics, others (please describe). Section II had two questions about attitudes toward doping and the use of medicines in daily life as athletes. Section III presented a hypothetical situation whereby the respondent would use a drug undetectable by doping control, win a gold medal and have a lifespan of only 5 years thereafter; the respondent was asked whether he or she would do this. In Section IV, questions were about dietary supplements. The first question asked whether the responder used dietary supplements and, if the answer was yes, the second question asked which supplements were used. Section V was comprised of a question on eating or drinking before playing a game.

This study was performed according to the Declaration of Helsinki and the guidelines of the ethics board of our university.

\section{Results}

The recovery rate of the questionnaire was $100 \%$ of those to whom it was distributed.

Responses to Question I-1 showed that there were 2 drug abusers (0.4\%) and 744 (99.6\%) non-abusers. In Question I-2, 1 drug abuser answered, "Yes" to the use of diuretics and the other gave no answer. There were no responses to Question I-3 to I-7.

In answering Question II-1, 144 (19.3\%) selected "good" about doping, 592 (79.1\%) selected "bad" and 12 (1.6\%) gave "no answer" (Figure 1). In Question II-2 (Figure 2) regarding whether the responder minded taking medicines, $152(20.3 \%)$ said "yes", 573 (74.6\%) said "no", and 23 (3.1\%) gave "no answer".

In Question III-1 regarding the hypothetical situation regarding drug abuse with the aim of winning a gold medal, $85(11.4 \%)$ answered "yes", 655 (87.5\%) "No", and 8 (1.1\%) gave "no answer" (Figure 3). As to Question III-2, one of those who answered "yes" said that it was only important to win the gold medal and another stated the desire to win a medal. One of those who answered "no" said that he/she did not want to win a medal if his/her life span would be shortened and another stated

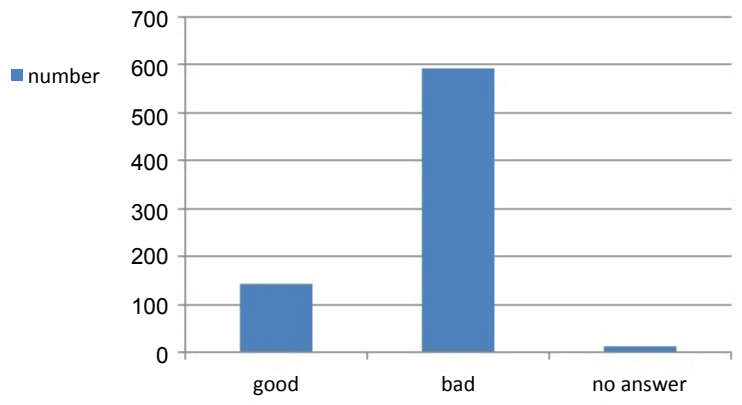

Figure 1: Response to Question II-1 on the self-completed questionnaire (Do you think doping is good or bad?)

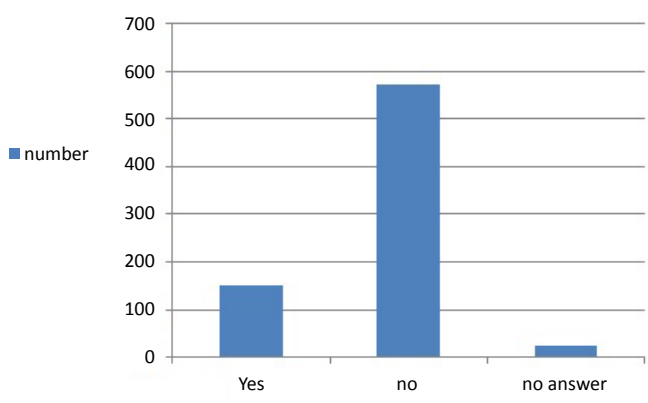

Figure 2: Response to Question II-2 on the self-completed questionnaire (Do you mind using medicines?)

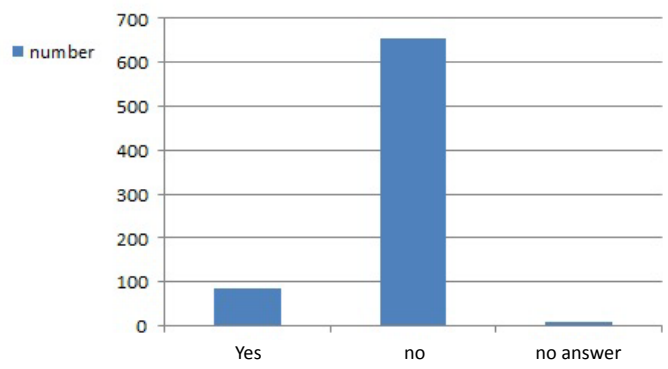

Figure 3: Response to hypothetical situation presented in Section III of the questionnaire whereby the respondent would use a drug undetectable by doping control, win a gold medal a have a lifespan of only 5 years thereafter. Responder was asked to declare whether he would or would not use the agent. Possible responses were "yes," "no" and "no answer".

that we should win a medal by our own skills without the aid of drugs.

In Question IV-1, which was on whether the responder used dietary supplements, "yes" was given by 218 (29.1\%) responders, "no" by $515(68.9 \%)$, and "no answer" by $15(2.0 \%)$ (Figure 4$)$. Responses to Question IV-2 showed that protein was used by 183 students, amino acids by 66 , vitamins by 62 , creatine by 42 , and iron by 27 , and anabolic agent by 6 , and a stimulant by 1 . As to Question $V$, which was what the responder might eat or drink before a game, there were no responders.

\section{Discussion}

It is important to examine the range and dimensions of the use of AAS. In answer to Question I-1, almost all of the students had not used a performance enhancing drug. Kindlundh et al. reported the results of an anonymous questionnaire on doping among Swedish high school students in 1998 and showed that about 3\% of male students used AAS in relation to sports activity [5]. Williamson administered questionnaires on drug abuse in sports, especially AAS in the UK in 1993 [6]. He had the impression that drug abuse was widespread among youths, especially high school students but found that $2.8 \%$ of students were using AAS with regard to sports in 1993. In 1996, a survey of the use of AAS by young Canadian students through a self-report questionnaire showed that the rate of anabolic steroid use was $2 \%$ in those 16 years of age [7]. In 1997, the report on the state of AAS use in 21 gymnasts in the UK showed that more than $10 \%$ of gymnasts of various ages were using AAS [8]. In 1997, the epidemiology of doping in sports was reviewed [9]. In that review, it was stated that the extent of sports doping and its potential health risks indicate that doping in sports should be considered a public health problem. Physicians must consider it as seriously as any other problem, focusing on the wider 


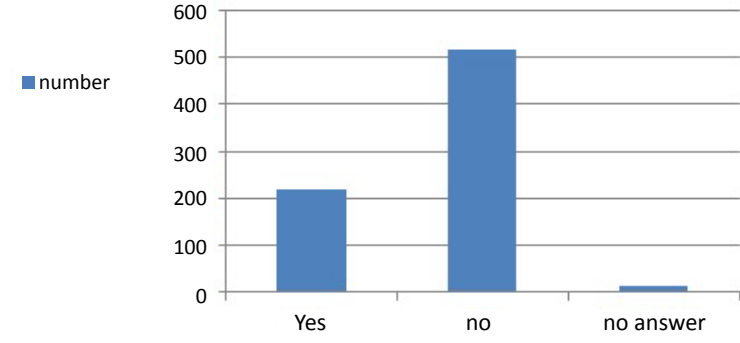

Figure 4: Response to Question IV-1 on the self-completed questionnaire (Are you using dietary supplements?)

issues beyond simply a list of prohibited substances, such as attitudes toward doping. In the US, the use of AAS among high school students is prevalent, and in $20011 \%$ to $2 \%$ of adolescent girls and $4 \%$ to $6 \%$ of adolescent boys have ever used AAS [10]. In Sweden, the same situation with regard to the use of AAS by adolescents was recognized [11]. In 2007, Laure and Binsinger reported on the state of drug abuse in sports in France [12]. They noted that $1.2 \%$ of pupils entering the first year of secondary school in France stated that they had taken doping agents at least once in the preceding 6 months; 4 years later this rate had risen to $3.0 \%$. Of users, $4 \%$ reported that they had experienced a health problem related to doping, and $44 \%$ reported that they had won at least one sports event as a result of drug use.

Although we did not show the results here, we have distributed the same anonymous questionnaire as described in this report for 5 years. In reality, the rate of use of illegal recreational drugs and performanceenhancing drugs in this physical education university is low. In Japan, the Japan Anti-Doping Agency (http://www.playtruejapan.org/) has announced statistics on the use of performance enhancing agents since 1997. In 2010, 258, 267 samples were examined and $1.08 \%$ were positive (http://www.medience.co.jp/doping/03.html). Since 1997, the rate has been below 2\%. Therefore it is thought that there may be fewer drug abusers in Japan than in other developed countries. However, in the survey reported here 2 students admitted to the use of drugs, and in the survey in 2010 one student admitted to the use of marijuana. Illegal recreational drugs or AAS might have been used. It was surprising that there were some drug abusers in a physical education college in Japan. It is of interest that no student has answered Questions I-3 to I-7 since the beginning of this investigation.

We asked questions to determine students' attitudes toward doping. In response to Question II-1, which was "What do you think about doping?" $80 \%$ of students selected "bad" and $20 \%$ selected "good". Over the previous 4 years of the study, that is, from 2008 to 2011, the response of "good" has ranged from 15 to $20 \%$. Although students have attended lectures about illegal drugs, they have not studied the doping control system as a class yet. It is important for elite athletes to become informed about doping.

In addition, we presented a hypothetical situation to elicit the attitude toward doping (Question III-1). About $10 \%$ of the responders would use drugs to win a medal even if they would die 5 years later, and about $20 \%$ indicated a positive attitude toward doping in sports. Against such a background, the habit of drug abuse in sports will spread if there is a strong motivation.

In 2001, Nilsson et al. reported that AAS abusers use alcohol, growth hormones, and narcotic drugs more than AAS non-users [11]. Laure et al. noted that users of doping agents take cannabis, tranquilizers, hypnotics, and creatine more than non-users [13] Peterson et al. reported similar results [14]. However, we could not confirm a case of using both AAS and illegal drugs as did these reports. As background, the use of these drugs has not spread among Japanese physical educational students.

German nonathletes, recreational athletes and competitive athletes performed poorly on a knowledge test regarding doping in general with an average below $60 \%$ in each case [15]. In our study, each year there were unclear answers to Q I-2 (What drugs are you using if you use performance enhancing drugs?). It is clear that they are not informed about the drugs they are using. It may be the same state from the viewpoint of knowledge of drug abuse. Buckman et al. said that athletes who used performance-enhancing substances compared with nonusers reported more alcohol-related behaviors and alcohol- and drug-userelated problems [16]. Although there were only a few drug users in our study, once such usage spreads, alcohol and various drug problems will spread. In Japan, we will have to warn athletes and others of this possibility. In Germany, the high prevalence of drug abuse in sports was clear. Furthermore the high prevalence of the use of illicit drugs, especially cocaine, was clear [17]. The use of AAS promotes the use of the other drugs [18]. Furthermore, users of performance-enhancing drugs statistically tend to use alcohol [16]. AAS or other performanceenhancing drugs introduce illicit drug use [19-21]. In our study, one case of marijuana abuse was recognized. At present, it is necessary to prevent the growth of the prevalence of illicit or performance enhancing drugs.

AAS abuse in Finnish adolescents was uncommon in a survey [22] Dietary supplement use is associated with frequent sports participation

\section{Questions about use of performance enhancing drugs \\ 1. Are you using performance enhancing drugs? Yes / No \\ 2. If you answered "yes", what are you using? Stimulant, anabolic agent (anabolic androgenic steroid, $\beta_{2}$ stimulant, and growth hormone), erythropoietin diuretics, and others \\ 3. If you are using an anabolic agent, what agent is it? \\ 4. If you are using an anabolic agent, what is your objective? \\ 5. If you are using an anabolic agent, what are its effects? \\ 6. If you are using an anabolic agent, do you have any side effecs? \\ 7. If you used a performance-enhancing drug, what is it? \\ II. Questions about attitudes toward doping and medicines in daily life as athletes. \\ 1. What do you think about doping? Good / Bad / No answer \\ 2. Do you mind using medicines, for example, when you catch cold? \\ III. If you could use a drug that would not be detected by doping control and would win a gold medal, would you do so even if your life span would only be $\mathbf{5}$ years thereafter? \\ 1. Would you use the drug? Yes / No \\ 2. If you have an opinion about this, write it here. \\ IV. Questions about dietary supplementation. \\ 1. Are you using dietary supplements? \\ 2. If "yes" is it any of the following: protein, amino acids, iron, creatine, and supplement compounded with anabolic agent, supplement with stimulant? \\ 3. If you answered yes, what dietary supplement are you using? \\ 4. If you answered yes, what is the objective? \\ 5. If you answered yes, what are the effects of the supplement? \\ 6. If you answered yes, have you had any side effects? \\ 7. Can you tell us what dietary supplementation you might use? \\ V. Can you tell me what you might eat or drink before you play a game?}

Table 1: Questionnaire about doping use, attitudes toward doping, and dietary supplements 
and poorer than average health, while AAS use is associated with health-compromising behaviors. This state is similar to Japan. Bahrke et al. reviewed identified risk factors for drug abuse in sports and the rate of AAS use according to geographical regions in the US and South Africa [23]. However, there have been no reports on differences in the rate of AAS use according to country and the cultural background of countries.

In our study, about $30 \%$ of the students used dietary supplements. Gardiner et al. reported that herbs and dietary supplements were used by $17 \%$ of US young adults [24]. The use of supplements was more prevalent than we expected. However, the motives for the use of dietary supplements were unclear in our study, as in the US.

We think that it is necessary to prevent the spread of drug abuse in sports and of illicit drug use in Japan. Tricker and Connolly reported that drug education could be effective in preventing drug abuse among student athletes [25]. Dawson emphasized the role of the physician in addressing the problem of the use of performance enhancing drugs [26]. Although anti-doping anti-illicit drug measures are taken from official or private viewpoints, still more must be done. We think that it is important provide instruction on these issues at school.

In conclusion, it was ascertained that there were fewer students abusing drugs in Japan than in other developed countries. However, about $20 \%$ of the students approved of the use of drugs in sports. Furthermore, about $10 \%$ of them indicated that they might use drugs in competition. It is necessary for the government to adopt effective measures to address this issue.

\section{Acknowledgements}

We would like to acknowledge all of the students who responded to our questionnaire.

\section{References}

1. Takahashi M, Tatsugi $Y$, Kohno $T$ (2007) Internet-based medical counseling on performance-enhancing drug abuse. J Med Soc Toho 54: 115-119.

2. Takahashi M, Tatsugi T, Kohno Y (2007) Telephone counseling of athletes abusing anabolic-androgenic steroids. J Sports Med Phys Fitness 47: 356-360.

3. Takahashi M, Tatsugi Y, Kohno T (2012) Analysis of communications about drug abuse among players of American football or athletes in Japan. GazzettaMedicaltaliana 171:157-164.

4. Meilman PW, Crace RK, Presley CA, Lyerla R (1995) Beyond performance enhancement: polypharmacy among collegiate users of steroids. J Am Coll Health 44: 98-104

5. Kindlundh AM, Isacson DG, Berglund L, Nyberg F (1998) Doping among high school students in Uppsala, Sweden: A presentation of the attitudes, distribution, side effects, and extent of use. Scand J Soc Med 26: 71-74.

6. Williamson DJ (1993) Anabolic steroid use among students at a British college of technology. Br J Sports Med 27: 200-201.

7. Melia P, Pipe A, Greenberg L (1996) The use of anabolic-androgenic steroids by Canadian students. Clin J Sport Med 6: 9-14.

8. Korkia P, Stimson GV (1997) Indications of prevalence, practice and effects of anabolic steroid use in Great Britain. Int J Sports Med 18: 557-562.

9. Laure P (1997) Epidemiologic approach of doping in sport. A review. J Sports Med Phys Fitness 37: 218-224.

10. Yesalis CE (2001) Use of steroids for self-enhancement: an epidemiologic/ societal perspective. AIDS Read 11: 157-160.
11. Nilsson S, Baigi A, Marklund B, Fridlund B (2001) The prevalence of the use of androgenic anabolic steroids by adolescents in a county of Sweden. Eur J Public Health 11: 195-197.

12. Laure $P$, Binsinger $C$ (2007) Doping prevalence among preadolescent athletes: a 4-year follow-up. Br J Sports Med 41: 660-663.

13. Laure P, Lecerf T, Friser A, Binsinger C (2004) Drugs, recreational drug use and attitudes towards doping of high school athletes. Int J Sports Med 25: 133-138.

14. Petersson A, Bengtsson J, Voltaire-Carlsson A, Thiblin I (2010) Substance abusers' motives for using anabolic androgenic steroids. Drug Alcohol Depend 111: 170-172.

15. Wanjek B, Rosendahl J, Strauss B, Gabriel HH (2007) Doping, drugs and drug abuse among adolescents in the State of Thuringia (Germany): prevalence, knowledge and attitudes. Int J Sports Med 28: 346-353.

16. Buckman JF, Yusko DA, White HR, Pandina RJ (2009) Risk profile of male college athletes who use performance-enhancing substances. J Stud Alcohol Drugs 70: 919-923.

17. Simon P, Striegel H, Aust F, Dietz K, Ulrich R (2006) Doping in fitness sports: estimated number of unreported cases and individual probability of doping Addiction 101: 1640-1644.

18. Skårberg K, Nyberg F, Engström I (2008) The development of multiple drug use among anabolic-androgenic steroid users: six subjective case reports. Subst Abuse Treat Prev Policy 3: 24-34.

19. Nocelli L, Kamber M, François Y, Gmel G, Marti B (1998) Discordant public perception of doping in elite versus recreational sport in Switzerland. Clin $J$ Sport Med 8: 195-200.

20. Black DL, Cawthon B, Robert T, Moser F, Caplan YH, et al. (2009) Multiple drug ingestion by ecstasy abusers in the United States. J Anal Toxicol 33: 143-147.

21. Strano Rossi S, Botrè $F$ (2011) Prevalence of illicit drug use among the Italian athlete population with special attention on drugs of abuse: a 10-year review. J Sports Sci 29: 471-476.

22. Mattila VM, Parkkari J, Laakso L, Pihlajamäki H, Rimpelä A (2010) Use of dietary supplements and anabolic-androgenic steroids among Finnish adolescents in 1991-2005. Eur J Public Health 20: 306-311.

23. Bahrke MS, Yesalis CE, Kopstein AN, Stephens JA (2000) Risk factors associated with anabolic-androgenic steroid use among adolescents. Sports Med 29: 397-405.

24. Gardiner P, Kemper KJ, Legedza A, Phillips RS (2007) Factors associated with herb and dietary supplement use by young adults in the United States. BMC Complement Altern Med 7: 39.

25. Tricker R, Connolly D (1996) Drug education and the college athlete: evaluation of a decision-making model. J Drug Educ 26: 159-181.

26. Dawson RT (2001) Drugs in sport - the role of the physician. J Endocrinol 170 170: $55-61$ 